\title{
COMPOSTOS FENÓLICOS TOTAIS E ATIVIDADE ANTIOXIDANTE DE CHÁS COMERCIALIZADOS NO BRASIL
}

\author{
RODRIGO APARECIDO MORAES-DE-SOUZA* \\ TATIANE LUIZA CADORIN OLDONI** \\ INGRIDY SIMONE RIBEIRO CABRAL*** \\ SEVERINO MATIAS DE ALENCAR ${ }^{* * *}$
}

\begin{abstract}
Este trabalho teve como objetivo avaliar o teor de compostos fenólicos totais e a atividade antioxidante de chás consumidos no Brasil. Avaliou-se o teor de compostos fenólicos totais pelo método do Folin Ciocalteu e a atividade antioxidante pelo sequestro do radical DPPH (porcentagem de inibição do radical DPPH; porcentagem de $\mathrm{DPPH}$ remanescente; coeficiente de inibição, $\mathrm{IC}_{50}$ ). As análises das seguintes infusões foram realizadas em triplicata: chá preto, chá verde, mate, camomila e anis (erva-doce) de três diferentes marcas ( $A, B$ e $C$ ). Os maiores teores de compostos fenólicos foram encontrados em chá verde $(C$ e $B)$, chá preto $(C)$ e mate (A) (teores superiores a $65 \mathrm{mg} E A G / g$ de chá). O chá verde $(\mathrm{C}$ e $\mathrm{B})$ foi o mais eficiente em termos de porcentagem de inibição do radical DPPH (valores acima de 90\%), de porcentagem de DPPH. remanescente (menos de 10\% da concentração inicial) e em termos de $\mathrm{IC}_{50}$ (valores inferiores a $150 \mu \mathrm{g}$ de massa seca/mL de infusão). O chá de camomila, percentualmente, apresentou os melhores índices, mas o parâmetro $\mathrm{IC}_{50}$ resultou em valores elevados que correspondem à baixa atividade antioxidante. Não houve correlação entre os teores de compostos fenólicos e a atividade antioxidante demonstrada pela percentagem de inibição e pela percentagem de DPPH remanescente. No entanto a correlação entre os teores de compostos fenólicos e a atividade antioxidante evidenciada pelo coeficiente de inibição $\left(I C_{50}\right)$ foi elevada $(r=0,92)$, indicando a existência de compostos com distintos potenciais antioxidantes.
\end{abstract}

PALAVRAS-CHAVE: CHÁ; ATIVIDADE ANTIOXIDANTE; COMPOSTOS FENÓLICOS.

* Doutor em Ciências, Centro de Energia Nuclear na Agricultura, Universidade de São Paulo (USP), Piracicaba, SP (e-mail: ramssp@yahoo.com.br).

** Docente, Departamento de Química, Universidade Tecnológica Federal do Paraná, Pato Branco, PR (e-mail: tatianeoldoni@utfpr.edu.br).

*** Doutoranda em Ciências, Centro de Energia Nuclear na Agricultura, USP, Piracicaba, SP (e-mail: ingridyribeiro@yahoo.com.br).

**** Livre-docente, Departamento de Agroindústria, Alimentos e Nutrição, Escola Superior de Agricultura "Luiz de Queiroz", USP, Piracicaba, SP (e-mail: alencar@esalq.usp.br). 


\section{INTRODUÇÃO}

Define-se chá como o produto do processamento de espécies vegetais (BRASIL, 2008), assim como a bebida obtida desses produtos por meio de infusão. Os chás têm sido estudados por apresentarem alta atividade antioxidante, sendo essa dependente do perfil de compostos fenólicos extraídos no processo de infusão. Tal atividade desperta interesse devido ao impacto positivo sobre as condições de saúde, vitalidade celular e corporal (ATOUl et al., 2005; FECKA e TUREK, 2007).

Diferentes métodos têm sido utilizados para se determinar a atividade antioxidante de alimentos, o que tem gerado resultados conflitantes. Alguns passos para a padronização de protocolos com a finalidade de avaliar os efeitos antioxidantes de determinada amostra foram sugeridos. Esses seriam a quantificação e a identificação dos compostos fenólicos presentes, seguidos pela determinação da atividade sequestrante de radical, assim como do efeito do solvente (BECKER, NISSEN e SKIBSTED, 2004).

A atividade antioxidante de chás vem sendo estudada por ensaios in vitro, porém poucos autores consideram os fatores que podem acarretar a variabilidade dos resultados. Tais fatores podem ser: os materiais, os métodos e as condições ambientais que caracterizam as diversas formas de determinação, assim como a forma de apresentação dos resultados. Outros aspectos decisivos são relativos à matéria-prima, pois as amostras apresentam diferentes perfis de compostos fenólicos dependendo das espécies vegetais, das partes das plantas utilizadas para fazer a infusão, das condições de plantio, colheita e armazenamento, assim como das condições de processamento, tais como secagem e inativação enzimática. Todos esses fatores somados ao solvente utilizado, água no caso de infusões, são importantes e devem ser considerados na determinação dos resultados (MORAES-DE-SOUZA et al., 2008).

O objetivo deste trabalho foi avaliar infusões obtidas de cinco tipos de chás de destacado consumo no Brasil de três marcas comerciais. Foram analisados o teor de compostos fenólicos totais e a atividade antioxidante pelo método de sequestro do radical DPPH', sendo os resultados expressos de três formas distintas (porcentagem de inibição, $I_{50}$ e porcentagem de DPPH. remanescente).

\section{MATERIAL E MÉTODOS}

\subsection{AMOSTRAS DE CHÁS}

As infusões foram obtidas de chá preto e chá verde [(Camellia sinensis (L.) O. Kuntze)], mate (Ilex paraguariensis A. St.-Hil.), camomila (Matricaria recutita L.) e anis ou erva-doce (Pimpinella anisum L.) de três diferentes marcas ( $\mathrm{A}, \mathrm{B}$ e $\mathrm{C}$ ), adquiridas no comércio de Piracicaba. Efetuou-se o preparo das infusões pela adição de $100 \mathrm{~mL}$ de água destilada (equivalente a 1/2 xícara de chá), à aproximadamente $100^{\circ} \mathrm{C}$, sobre 1 grama de chá em temperatura ambiente por 10 minutos. A combinação do tempo (10 minutos) e temperatura inicial da infusão $\left(100^{\circ} \mathrm{C}\right)$ utilizada neste estudo tem sido descrita por vários autores como sendo eficiente para a extração de compostos fenólicos em ervas (LIMA, MELO e LIMA, 2004; KATALINIC et al., 2006; SU et al., 2006). Em seguida, os extratos foram filtrados e as infusões armazenadas em frascos de vidro sob refrigeração $\left(5^{\circ} \mathrm{C}\right)$. Utilizou-se como controle positivo solução de quercetina na concentração de $5 \mathrm{mg} / \mathrm{mL}$.

\subsection{TEOR DE COMPOSTOS FENÓLICOS TOTAIS}

Efetuou-se a análise do teor de compostos fenólicos totais de cada infusão espectrofotometricamente, conforme o método colorimético de Folin-Ciocalteu, utilizando ácido 
gálico como padrão (SINGLETON e ROSSI, 1965). Uma alíquota de $0,5 \mathrm{~mL}$ das infusões diluídas em água destilada na proporção $1: 5(\mathrm{v} / \mathrm{v})$ foi transferida para tubo de ensaio, no qual foram adicionados 2,5 mL do reagente Folin-Ciocalteu, diluído em água destilada 1:10 (v/v). Agitouse a mistura que permaneceu em repouso por 5 minutos. Em seguida, foram adicionados $2 \mathrm{~mL}$ de carbonato de sódio $4 \%(\mathrm{p} / \mathrm{v})$ e os tubos deixados em repouso por 2 horas, ao abrigo da luz. A absorbância foi medida a $740 \mathrm{~nm}$ em espectrofotômetro (UV Mini 1240, Shimadzu Co.). Os resultados dos teores de compostos fenólicos totais foram expressos como equivalentes de ácido gálico (mg EAG/g).

\subsection{ATIVIDADE ANTIOXIDANTE}

A mistura de reação para a medida da atividade sequestrante do radical DPPH (BRANDWILLIAMS, CUVELIER e BERSET, 1995) foi constituída pela adição de $0,5 \mathrm{~mL}$ das infusões diluídas $1: 5(\mathrm{v} / \mathrm{v})$ em água destilada, $3 \mathrm{~mL}$ de etanol e $0,3 \mathrm{~mL}$ da solução do radical DPPH 0,5 mM em etanol para análise. Após 45 minutos de incubação, a absorbância foi determinada em espectrofotômetro a $517 \mathrm{~nm}$. Para cada amostra de infusão foi realizado teste em branco, com adição de etanol em substituição à solução de DPPH $0,5 \mathrm{mM}$. O controle negativo consistiu na substituição da solução que continha a infusão por igual volume de água destilada. Os resultados foram expressos de três formas distintas: porcentagem de inibição e $I_{50}$ (KULISIC, DRAGOVIC-UZELAC e MILOS, 2006) e porcentagem de DPPH remanescente (ATOUI et al., 2005).

\subsubsection{Porcentagem de Inibição}

A capacidade de determinado composto inibir a oxidação de substrato oxidável pode ser simulada por meio da redução química do radical $\mathrm{DPPH}$, obtida pela doação de prótons de hidrogênio do composto ao radical. Essa simulação tem sido denominada "porcentagem de inibição" ou "porcentagem de sequestro de DPPH" (KULISIC, DRAGOVIC-UZELAC e MILOS, 2006), sendo calculada pela fórmula 1 :

Em que:

$$
\% \text { inibição }=\left[\left(\mathrm{A}_{\mathrm{C}(0)}-\mathrm{A}_{\mathrm{A(t)}}\right) / \mathrm{A}_{\mathrm{C}(0)}\right] \times 100
$$

$A_{A(t)}=$ absorbância da amostra após 45 minutos de repouso; e

$A_{C(o)}=$ absorbância do controle negativo no momento do preparo da solução.

\subsubsection{Coeficiente de Inibição $\left(\mathrm{IC}_{50}\right)$}

O coeficiente de inibição $\left(\mathrm{IC}_{50}\right)$, ou seja, a concentração necessária para se inibir $50 \%$ da oxidação do substrato oxidável foi obtido pela equação da reta gerada da plotagem das porcentagens de inibição associadas a cinco níveis de concentração para cada infusão. Quanto menor o IC ${ }_{50}$, melhor é a atividade antioxidante (KULISIC, DRAGOVIC-UZELAC e MILOS, 2006). A concentração de amostra, equivalente a $50 \%$ da absorbância do DPPH, foi calculada graficamente.

\subsubsection{Porcentagem de DPPH remanescente}

A concentração de DPPH remanescente no meio reativo foi calculada a partir da curva de calibração. É possível se determinar qual a quantidade de DPPH restante após a reação ter sido completada (HUANG, OU e PRIOR, 2005). A porcentagem de DPPH. remanescente foi calculada pela fórmula 2 :

$$
\% \text { DPPH remanescente }=100 \times[\mathrm{DPPH}]_{\mathrm{T}} /[\mathrm{DPPH}]_{\mathrm{T}=0}
$$

Em que:

$[\mathrm{DPPH}]_{\mathrm{T}}=$ concentração de DPPH no tempo de equilíbrio (45 minutos); e $[\mathrm{DPPH}]_{\mathrm{T}=0}=$ concentração de DPPH no tempo zero. 


\section{RESULTADOS E DISCUSSÃO}

Os maiores teores de compostos fenólicos foram encontrados para infusões de chá verde (marcas $\mathrm{C}$ e B), chá preto (marca $\mathrm{C}$ ) e mate (marca A), todas apresentando valores superiores a $65 \mathrm{mg}$ EAG/g de chá. Os menores teores foram constatados nas três marcas de chá de anis, seguidas pelas três marcas de chá de camomila, todas com valores inferiores a 20 mg GAE/g de chá (Tabela 1).

O método de Folin-Ciocalteu é muito utilizado para investigar o conteúdo de compostos fenólicos totais. O reagente Folin-Ciocalteu consiste em solução ácida amarela contendo íons poliméricos complexos formados de heteropoliácidos de molibdênio e tungstênio. Esse reagente oxida os fenolatos, resultando na produção de complexo azul molibdênio-tungstênio que pode ser detectado espectrometricamente a $765 \mathrm{~nm}$ (SINGLETON, ORTHOFER e LAMUELA, 1999). O perfil de compostos fenólicos varia muito entre as diversas espécies vegetais. Alguns dos principais compostos fenólicos estudados, pertencentes às classes flavonol e flavanol (catequinas) apresentam teores bem distintos entre os vários tipos de chás (MATSUBARA e RODRIGUEZ-AMAYA, 2006). Dependendo de suas estruturas químicas, os compostos fenólicos apresentam diferentes potenciais antioxidantes (WILLIAMS, SPENCER e RICE-EVANS, 2004), portanto a quantificação de compostos fenólicos totais é apenas um dos parâmetros na determinação da atividade antioxidante.

\section{TABELA 1 - TEOR DE FENÓLICOS TOTAIS ENCONTRADOS NAS AMOSTRAS DE CHÁS E INFUSÕES, EM EQUIVALENTES DE ÁCIDO GÁLICO}

\begin{tabular}{lc}
\hline Amostras & Fenólicos Totais (mg/g chá)* $^{*}$ \\
\hline Anis - A & $8,90 \pm 1,26^{\mathrm{hi}}$ \\
Anis - B & $5,24 \pm 0,45^{\mathrm{j}}$ \\
Anis - C & $6,17 \pm 1,64^{\mathrm{ij}}$ \\
Camomila - A & $11,61 \pm 1,50^{\mathrm{h}}$ \\
Camomila - B & $11,61 \pm 0,32^{\mathrm{h}}$ \\
Camomila - C & $15,49 \pm 0,19^{\mathrm{g}}$ \\
Mate - A & $68,74 \pm 1,68^{\mathrm{c}}$ \\
Mate - B & $57,04 \pm 1,41^{\mathrm{e}}$ \\
Mate - C & $49,34 \pm 2,30^{\mathrm{f}}$ \\
Chá preto - A & $62,85 \pm 1,05^{\mathrm{d}}$ \\
Chá preto - B & $62,91 \pm 0,39^{\mathrm{d}}$ \\
Chá preto - C & $74,39 \pm 0,68^{\mathrm{b}}$ \\
Chá verde - A & $59,18 \pm 0,78^{\mathrm{e}}$ \\
Chá verde - B & $72,14 \pm 1,52^{\mathrm{bc}}$ \\
Chá verde - C & $103,98 \pm 0,19^{\mathrm{a}}$ \\
\hline
\end{tabular}

* Valor = média \pm o desvio padrão $(n=3)$.

Letras diferentes indicam médias estatisticamente diferentes ao nível de $5 \%$ (Teste de Tukey $p<0,05)$.

Atoui e colaboradores (2005) encontraram os maiores teores de compostos fenólicos em chá verde, seguido pelo chá preto, enquanto valores bastante inferiores foram verificados para as infusões de camomila. Katalinic e colaboradores (2006), comparando infusões de 70 espécies vegetais, verificaram teores reduzidos para camomila. Lima, Melo e Lima (2004) obtiveram os mais expressivos índices em chá preto e mate, enquanto camomila e anis apresentaram baixos teores.

O uso de modelos simplificados para avaliar a atividade antioxidante é muito importante para estudos que visam determinar essa propriedade biológica dos alimentos. Um dos métodos mais usados para verificar a capacidade antioxidante consiste em avaliar a atividade sequestradora do radical 2,2-difenil-1-picril-hidrazila (DPPH·), de coloração púrpura, que absorve no comprimento de onda de 515-517 nm. A ação de um antioxidante ou uma espécie radicalar $(\mathrm{R} \cdot)$ reduz o $\mathrm{DPPH}, \cdot$ formando 2,2-difenilpicril-hidrazina (DPPH-H) de coloração amarela, com consequente desaparecimento da banda de absorção, sendo a mesma monitorada pelo decréscimo da absorbância. O método de DPPH é muito utilizado por ser rápido, sensível e não 
exigir equipamentos e reagentes difíceis de serem obtidos (KOLEVA et al., 2006). Entretanto, esse método tem gerado diferentes formas de apresentação de resultados, entre as principais a determinação da porcentagem de inibição (quantidade de DPPH• reduzido pelo antioxidante); a porcentagem de DPPH • remanescente no meio reacional e $I_{50}$ (HUANG, OU e PRIOR, 2005). Autores que estudaram a atividade antioxidante de infusões utilizaram para expressar os resultados algumas das formas citadas neste trabalho (KARORI et al., 2007; BUYUKBALCl e EL, 2008; DALL'ACQUA et al., 2008).

Em termos de porcentagem de inibição destacaram-se as infusões de chá verde (C e B) e camomila (B), todas apresentando valores superiores a $90 \%$ de inibição, sendo esses estatisticamente inferiores à quercetina. Estatisticamente os índices mais baixos foram observados (Figura 1) nos chás de anis das marcas $B$ e $C$ e no chá mate da marca $C$.

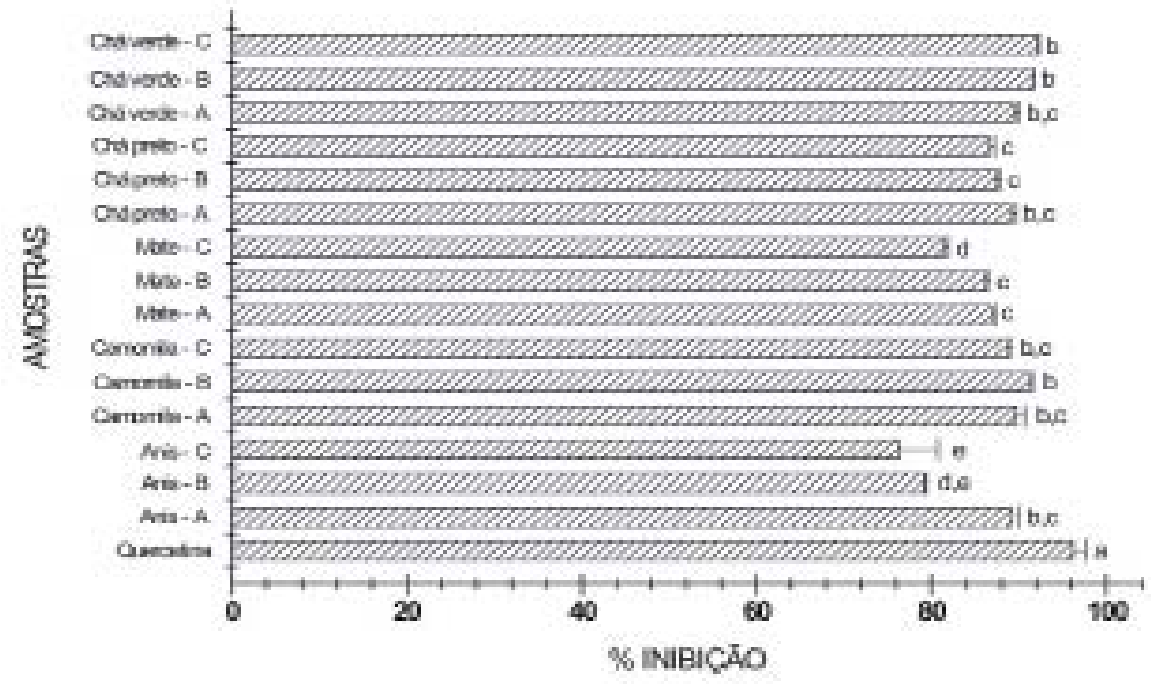

\section{FIGURA 1 - ATIVIDADE SEQUESTRANTE DO RADICAL LIVRE DPPH PELO PADRÃO QUERCETINA E INFUSÕES}

Médias e desvios padrões estão indicados. Letras diferentes indicam médias estatisticamente diferentes ao nível de $5 \%$ (Teste de Tukey $\mathrm{p}<0,05$ ).

Moraes-de-Souza e colaboradores (2008) analisaram chás comerciais e encontraram para porcentagem de inibição a seguinte ordem: camomila $=$ anis $>$ chá verde $=$ chá preto $>$ mate.

Em termos de $\mathrm{IC}_{50}$, os melhores resultados foram observados para chá verde $(\mathrm{C}, \mathrm{B}, \mathrm{A})$ (valores inferiores a $150 \mu \mathrm{g}$ de massa seca/mL de infusão), seguidos pelas três marcas de chá preto. Novamente os resultados menos expressivos foram encontrados para o chá de anis, especialmente das marcas A e B (Figura 2).

Em termos de DPPH remanescente, as infusões de chá verde (C e B) e camomila (B) foram as mais eficientes restando menos de $10 \%$ da concentração inicial de DPPH após 45 minutos de reação. Também foram estatisticamente diferentes da quercetina, utilizada como padrão de referência (Figura 3).

A forma de expressar os resultados de atividade antioxidante em termos de DPPH. remanescente para chás não foi encontrada na literatura. Porém Argolo e colaboradores (2004) utilizaram o DPPH remanescente para expressar os resultados da atividade antioxidante dos extratos de folhas de Bauhinia monandra, conhecida popularmente por "árvore orquídea" ou "asas de anjo". Esses autores descreveram os extratos aquoso, etanólico, clorofórmico e de acetato de etila como sendo os mais eficientes, restando entre 35 e $40 \%$ da concentração inicial de DPPH. após 30 minutos de reação. 


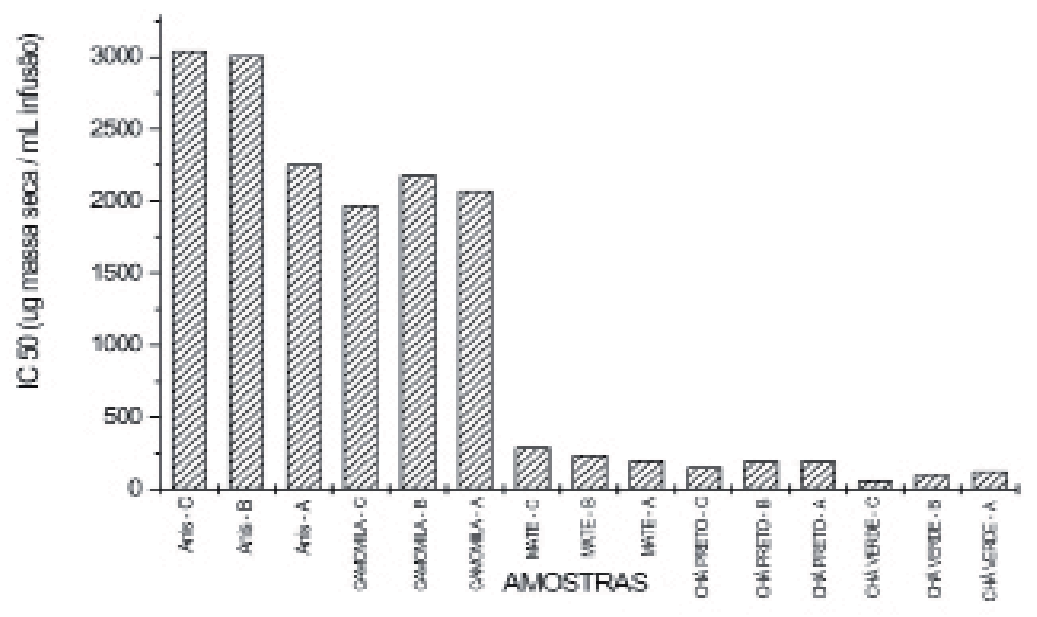

\section{FIGURA 2 - COEFICIENTE DE INIBIÇÃO (IC $\left.{ }_{50}\right)$ APRESENTADO PELAS INFUSÕES DE CHÁS}

Em termos de avaliação da capacidade antioxidante pelo método de sequestro do radical DPPH, não existe consenso sobre a melhor maneira de expressar os resultados. Analisando os resultados obtidos verificou-se que quando esses foram expressos em termos de porcentagem de inibição e DPPH remanescente, as infusões de chá verde e camomila foram as mais eficientes. No entanto, quando os resultados foram expressos em termos de $\mathrm{IC}_{50}$, a camomila apresentou os piores índices, sendo superior apenas ao anis.

O método mais indicado traduz melhor os objetivos do trabalho e dessa forma, quando diversas amostras são avaliadas (screening), a porcentagem de inibição é mais indicada por ser de execução mais simples e rápida. Já o método de $I C_{50}$ se torna o mais indicado quando se pretende avaliar de forma mais detalhada a ação do antioxidante, determinar qual a massa necessária desse para reduzir em $50 \%$ a concentração inicial de DPPH no meio, assim como a cinética de reação - visto que as reações com o radical DPPH diferem entre os compostos em três tipos de cinética, rápida, intermediária e lenta (BRAND-WILLIANS, CUVELIER e BERSET, 1995).

A correlação entre os teores de compostos fenólicos totais e a atividade antioxidante em termos de porcentagem de inibição e de concentração de DPPH remanescente foi positiva, porém baixa ( $r=0,40$ e 0,15 respectivamente). Tal fato demonstra a existência de compostos com distintos potenciais antioxidantes. No entanto, foi verificado $r=0,92$ entre o teor de compostos fenólicos totais e os resultados obtidos pelo $I C_{50}$, o que evidencia forte relação entre a concentração dos compostos fenólicos e a atividade antioxidante apresentada.

Os resultados obtidos estão de acordo com os apresentados por Moraes-de-Souza e colaboradores (2008), com $r=0,25$ entre o teor de compostos fenólicos totais e a porcentagem de inibição pelo método DPPH e $r=0,93$ entre o teor de compostos fenólicos totais e $I C_{50}$. Katsube e colaboradores (2004), utilizando o $I_{50}$ para demonstrar a atividade antioxidante de vegetais comestíveis evidenciaram alta correlação entre o teor de compostos fenólicos totais e o $\mathrm{IC}_{50}$. Kulisic, Dragovic-Uzelac e Milos (2006), estudando infusões de orégano, tomilho e serpilho, encontraram a seguinte sequência para a atividade antioxidante em termos de $\mathrm{IC}_{50}$ : orégano $(0,07 \mathrm{~g} / \mathrm{L})>$ tomilho $(0,3 \mathrm{~g} / \mathrm{L})>$ serpilho $(0,45 \mathrm{~g} / \mathrm{L})$. Já em termos de porcentagem de inibição, os melhores índices seguiram a ordem: serpilho $(91,55 \%)>$ orégano $(85,00 \%)>$ tomilho $(69,05 \%)$. Esses autores afirmaram que tal discrepância deve-se às distintas composições, em termos de compostos fenólicos, existentes entre diferentes espécies vegetais. Esses resultados demonstram que as mesmas espécies vegetais podem apresentar diferentes composições químicas e consequentemente distintas atividades antioxidantes quando são obtidas de várias marcas comerciais de chás. Isto pode ser 
explicado pelas variações nas matérias-primas (condições de cultivo e colheita) e pelas condições de processamento, influenciando assim a qualidade do produto final disponível ao consumidor.

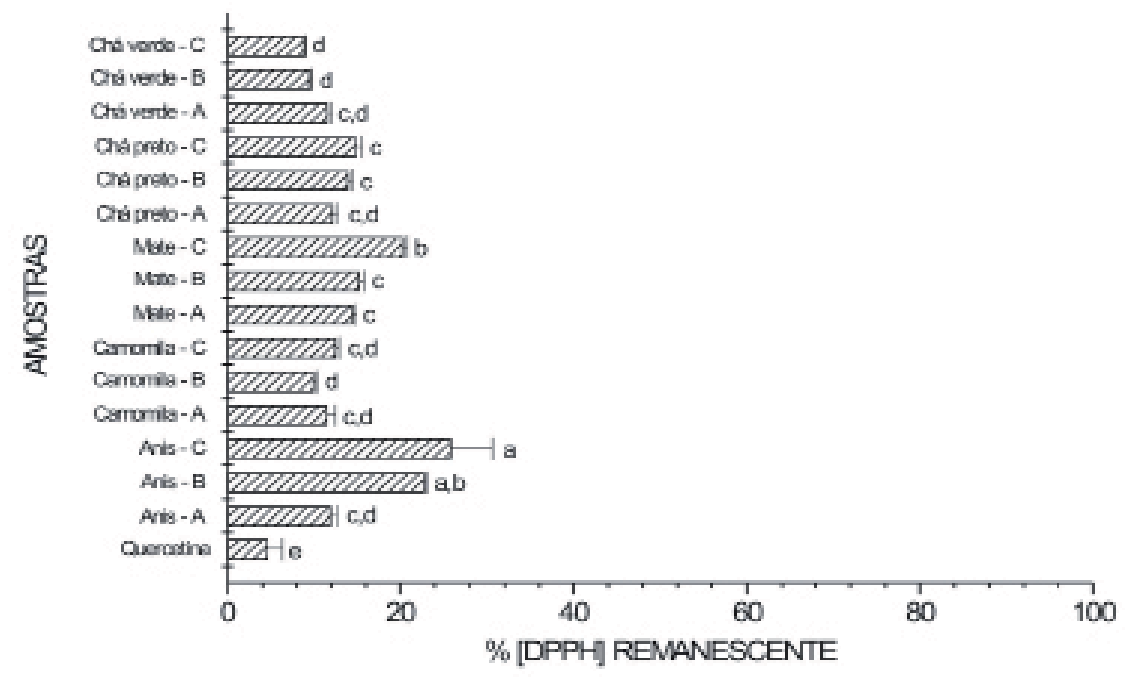

\section{FIGURA 3 - PERCENTAGEM DE DPPH REMANESCENTE APRESENTADA PELO PADRÃO QUERCETINA E INFUSÕES}

Médias e desvios padrões estão indicados. Letras diferentes indicam médias estatisticamente diferentes ao nível de $5 \%$ (Teste de Tukey $\mathrm{p}<0,05$ ).

\section{CONCLUSÃO}

Os resultados obtidos neste estudo demonstraram que as mesmas espécies vegetais podem apresentar diferentes composições químicas e consequentemente atividades antioxidantes distintas quando são obtidas de diferentes marcas comerciais de chás. Evidenciaram também a importância da forma de se apresentar os resultados do mesmo método de determinação de atividade antioxidante, tendo em vista o caso do chá de camomila. Em termos de porcentagem de inibição ou de porcentagem de DPPH· remanescente, o chá de camomila classifica-se como um dos mais ativos antioxidantes, enquanto em termos de $\mathrm{IC}_{50}$, o mesmo apresenta um dos piores potenciais, sendo menos eficiente que chá verde, chá preto ou chá mate.

\section{ABSTRACT}

\section{TOTAL PHENOLIC COMPOUNDS AND ANTIOXIDANT ACTIVITY OF TEAS SOLD IN BRAZIL}

This research aimed to evaluate the total phenolic content and the antioxidant activity of different brand's teas consumed in Brazil. Total phenolic content was evaluated by Folin Ciocalteu and antioxidant activity was determined by $\mathrm{DPPH} \bullet$ radical scavenging assay (by percentage of inhibition of DPPH• radical; percentage of remaining $\mathrm{DPPH} \bullet$; coefficient of inhibition, $\left.\mathrm{IC}_{50}\right)$. The analysis of the following teas were performed in triplicate: black tea, green tea, mate, chamomile and anise from three different brands (A, B and C). The highest levels of phenolic compounds was found in green tea (C and B), black tea (C) and mate (A) (values above $65 \mathrm{mg}$ GAE /g of tea). Green tea (C and B) was the most efficient in terms of percentage of inhibition of DPPH. radical (values above $90 \%$ ), the percentage of DPPH. remaining (less than $10 \%$ of initial concentration) and in terms of $\mathrm{IC}_{50}$ (below $150 \mathrm{mg}$ dry weight / $\mathrm{mL}$ of infusion). The chamomile tea, in percentage terms, showed the best rates, however, when the $\mathrm{IC}_{50}$ parameter was evaluated, high values were observed, therefore low antioxidant activity. There was no correlation between phenolic compounds levels and antioxidant activity demonstrated by the percentage of inhibition and the percentage of remaining DPPH. but the correlation between the levels of phenolic compounds and antioxidant activity shown by the coefficient of inhibition (IC50) was high $(r=0.92)$, thus demonstrating the existence of compounds with different antioxidant potential. 


\section{REFERÊNCIAS}

1 ARGOLO, A.C.C.; SANT'ANA, A.E.G.; PLETSCH, M.; COELHO, L.C.B.B. Antioxidant activity of leaf extracts from Bauhinia monandra. Bioresource Technology, v. 95, n.1, p. 229-233, 2004.

2 ATOUI, A.K. MANSOUR, A.; BOSKOU, G.; KEFALAS, P. Tea and herbal infusions: their antioxidant activity and phenolic profile. Food Chemistry, v. 89, n. 1, p. 27-36, 2005.

3 BECKER, E.M.; NISSEN, L.R.; SKIBSTED, L.H. Antioxidant evaluation protocols: food quality or health effects. European Food Research Technology, v. 219, n.6, p. 561-571, 2004.

4 BRAND-WILLIAMS, W.; CUVELIER, M.E.; BERSET, C. Use of free radical method to evaluate antioxidant activity. Lebesmittel-Wissenschaft und Technologie, v. 28, n.1, p. 25-30, 1995.

5 BRASIL. Ministério da Saúde. Agência Nacional de Vigilância Sanitária (ANVISA). Resolução de Diretoria Colegiada (RDC) $n^{\circ} .277$, de 22 de setembro de 2005. Aprova o regulamento técnico para café, cevada, chá, erva-mate e produtos solúveis. Disponível em: http://www.anvisa.gov.br Acesso em: 8 mar. 2008.

6 BUYUKBALCI, A.; EL, S.N. Determination of "in vitro" antidiabetic effects, antioxidant activities and phenol contents of some herbal teas. Plant Foods for Human Nutrition, v.63, n. 1, p. 27-33, 2008.

7 DALL'ACQUA, S.; CERVELLATI, R.; LOI, M.C.; INNOCENTI, G. Evaluation of "in vitro" antioxidant properties of some traditional Sardinian medicinal plants: investigation of the high antioxidant capacity of Rubus ulmifolius. Food Chemistry, v. 106, n.2, p. $745-749,2008$.

8 FECKA, I.; TUREK, S. Determination of water-soluble polyphenolic compounds in commercial herbal teas from Lamiaceae: peppermint, melissa and sage. Journal of Agricultural and Food Chemistry, v. 55, n. 26, p. 10908-10917, 2007.

9 HUANG, D.; OU, B.; PRIOR, R.L. The Chemistry behind antioxidant capacity assays. Journal of Agricultural and Food Chemistry, v. 53, n.1, p. 1841-1847, 2005.

10 KARORI, S.M.; WACHIRA, F.N.; WANUOKO, J.K.; NGURE, R.M. Antioxidant capacity of different types of tea products. African Journal of Biotechnology, v. 6, n.19, p. 2287-2296, 2007.

11 KATALINC, V.; MILOS, M.; KULISIC, T.; JUKIC, M. Screening of 70 medicinal plant extracts for antioxidant capacity and total phenols. Food Chemistry, v. 94, n.4, p. 550-557, 2006.

12 KATSUBE, T.; TABATA, H.; OHTA, Y.; YAMASAKI, Y.; ANUURAD, E.; SHIWAKU, K.; YAMANE, Y. Screening for antioxidant activity in edible plant products: comparison of low-density lipoprotein oxidation assay, DPPH radical scavenging assay, and Folin-Ciocalteu assay. Journal of Agricultural and Food Chemistry, v. 52, n. 8, p. 2391-2396, 2004.

13 KOLEVA, I.I.; VAN BEEK, T.A.; LINSSEN, J.P.H.; de GROOT, A.; EVSTATIEVA, L.N. Screening of plant extracts for antioxidant activity: a comparative study on three testing methods. Phytochemical Analysis, v. 13, n.1, p. 8-17, 2006.

14 KULISIC, T.; RADONIC, A.; KATALINIC, V.; MILOS, M. Use of different methods for testing antioxidative activity of oregano essential oil. Food Chemistry, v. 85, n.4, p. 633-640, 2004.

15 KULISIC, T.; DRAGOVIC-UZELAC, V.; MILOS, M. Antioxidant activity of aqueous tea infusions prepared from oregano, thyme and wild thyme. Food Technology and Biotechnology, v. 44, n.4, p. 485-492, 2006.

16 LIMA, V.L.A.G.; MELO, E.A.; LIMA, D.E.S. Teor de compostos fenólicos totais em chás brasileiros. Brazilian Journal of Food Technology, v. 7, n.2, p 187-190, 2004.

17 MATSUBARA, S.; RODRIGUEZ-AMAYA, D.B. Conteúdo de miricetina, quercetina e kaempferol em chás comercializados no Brasil. Ciência e Tecnologia de Alimentos, v. 26, n.2, p. 380-385, 2006.

18 MORAES-DE-SOUZA, R.A.; OLDONI, T.L.C.; REGITANO-D'ARCE, M.A.B.; ALENCAR, S.M. Antioxidant activity and phenolic composition of herbal infusions consumed in Brazil. Ciencia y Tecnología Alimentaria, v.6, n.1, p. 41-47, 2008.

19 SINGLETON, V.L.; ROSSI Jr, J.A. Colorimetry of total phenolics with phosphomolybdic-phosphotungstic acid reagents. American Journal of Enology and Viticulture, v. 16, n. 1, p. 144-158, 1965.

20 SINGLETON, V.L.; ORTHOFER, R.; LAMUELA, R.M. Analysis of total phenols and other oxidation substrates and antioxidants by means of Folin-Ciocalteu reagent. Methods of Enzymology, v.299, n.1, p.152-178, 1999.

21 SU, X.; DUAN, J.; JIANG, Y.; SHI, J.; KADUKA, Y. Effects of soaking conditions on the antioxidant potentials of oolong tea. Journal of Food Compostion Analysis, v. 19, n.4, p.348-353, 2006.

22 WILLIAMS, R.J.; SPENCER, J.P.E.; RICE-EVANS, C. Flavonoids: antioxidants or signalling molecules? Free Radical Biological Medical, v. 36, n.7, 838-849, 2004. 